\title{
AN ANALYSIS OF EXCAVATION SUPPORT SAFETY BASED ON EXPERIMENTAL STUDIES
}

\author{
KAROLINA GORSKA, MAREK WYJADŁOWSKI \\ Wrocław University of Technology, Poland. \\ E-mail: Karolina.Gorska@pwr.edu.pl, Marek.Wyjadlowski@pwr.edu.pl
}

\begin{abstract}
The article presents the results of inclinometric measurements and numerical analyses of soldier-pile wall displacements. The excavation under investigation was made in cohesive soils. The measurements were conducted at points located at the edge of the cantilever excavation support system. The displacements of the excavation support observed over the period of three years demonstrated the pattern of steady growth over the first two months, followed by a gradual levelling out to a final plateau. The numerical analyses were conducted based on 3D FEM models. The numerical analysis of the problem comprise calculations of the global structural safety factor depending on the displacement of the chosen points in the lagging and conducted by means of the $\varphi / c$ reduction procedure. The adopted graphical method of safety estimation is very conservative in the sense that it recognizes stability loss quite early, when one could further load the medium or weaken it by further strength reduction. The values of the $M_{s f}$ factor are relatively high. This is caused by the fact that the structure was designed for excavation twice as deep. Nevertheless, the structure is treated as a temporary one.
\end{abstract}

Key words: soldier-pile wall, inclinometer measurements, $\varphi / c$ reduction procedure

\section{INTRODUCTION AND PROBLEM DEFINITION}

The article presents the results of field studies and numerical analyses of excavation support displacements. A better understanding of mechanisms involved in soil-structure interaction in excavations could reduce costs and help avoid potential problems. Designing a retaining structure should be consistent with the EN 1997-1 Eurocode 7 standard [20]. It is particularly important when the support works as a permanent structure. Estimating the predicted displacements at the design stage is essential for ensuring safety. Zhang and $\mathrm{Ng}$ [19] point out that geotechnical structures are more often governed by allowable displacement requirements than by ultimate limit requirements.

The article discusses the results of three-year long observations of displacements of a soldier-pile wall. In order to estimate the excavation support displacements, inclinometer measurements were conducted on a cantilever wall securing a 2-metre deep excavation. They enabled determining real displacements of the excavation support, and, based on them, the deflection of the support towards the excavation. During the experiment, an increase in pile displacement was observed, which could be explained by a deterioration in the geotechnical parameters of soil. This led to an increase in the active and a reduction in the passive earth pressure. The displacements of the top of the wall observed during these three years exceeded the displacements calculated for the initial geotechnical parameters. In the final stage of the observation, the displacements stabilized.

The numerical analyses were conducted based on 3D FEM models. This led to good approximation of the real work of the soldier-pile wall. The solution of the problem involved calculations of the displacement-related global structural safety factor, which were performed by means of the $\varphi / c$ reduction procedure. These numerical calculations enabled estimating changes in the global safety factor occurring during the observation of the excavation support.

Periodic systems of laterally loaded piles are widespread in engineering. The common feature of these geo-structural systems is that a drilled pile is loaded horizontally and this kind of load governs the design with respect to both ultimate and serviceability limit states [18]. The existing methods of analysing single laterally loaded piles can be generally divided into the following categories: (a) the limit state method; (b) the subgrade reaction method; (c) the $p-y$ method; (d) the elasticity method; and (e) the finite element method. 
The problem of piles submitted to lateral loads has been analysed by numerous researchers, starting from the classic work of Broms [3], [4]. Broms' method is based on the earth pressure theory with a simplifying assumption for the distribution of ultimate soil resistance along the pile length. This method is applicable to both short and long piles.

The subgrade reaction method [12], and the $p-y$ method [13], [14], employing beam-on-elastic-foundation assumptions, are widely used because of their simplicity and reasonable accuracy.

Recent works [11], [15] have been devoted mainly to 3D FEM elasto-plastic analyses of pile-soil systems. A FEM solution must start with constitutive modelling of in situ soil, then the effect of the pile installation must be modelled and finally the solution must address the influence of loading [16].

\section{TECHNOLOGY OUTLINE}

A soldier-pile wall is a retaining structure composed of vertical piles and horizontal lagging. The piles are made predominantly of structural steel. The lagging, usually built of squared timber, is mounted between the piles in several stages as the excavation is deepened and successive soil layers are uncovered. It is difficult to build such a structure in non-cohesive soils like uniform sands as the uncovered soil should be capable of maintaining momentary stability until the lagging is mounted. What is crucial for displacements of the structure at the service stage is the behaviour of vertical piles, which work like piles loaded with a lateral force and a moment. A soldier-pile wall is predominantly a temporary structure and it usually stays in place after the excavation work is completed. The lifetime of the structure is limited and no change in geotechnical soil parameters is predicted.

\section{SUBSOIL CONDITIONS AND PARAMETERS}

The excavation under investigation was made in cohesive soils. The soil conditions after [7] are shown in Table 1.

The surface layer is made up of uncontrolled fills and alluvia, whose thickness is up to $1.00 \mathrm{~m}$. They are underlain with a layer of cohesive glacial sandy clays containing pebbles and gravel. Their plasticity, determined from laboratory study results is $I_{L}=0.05$. The next layer is made up of cohesive glacial silty and sandy clays with pebbles. Their plasticity, determined from laboratory study results, is $I_{L}=0.15$.

The excavation support works like a structure with a cantilever static scheme. The basic element consists of piles made of 9.0-metre long HEB 300 profiles, spaced at 3.00-metre intervals. During the experiment, the piles were embedded in soil to the depth of $7.0 \mathrm{~m}$. The lagging is made of $12 \mathrm{~cm}$ thick pine wood class C 27 .

\section{INCLINOMETER MEASUREMENTS AND RESULTS}

The investigations were conducted at three points located at the edge of the excavation support system. Two of these points were prepared halfway the length of the lagging. The ABS inclinometer casing in the form of a special grooved tube was installed into a drillhole and the remaining space was filled with grout [6]. One point was made of a $40 \times 40 \times 2$ profile welded to a soldier pile (HEB300). A zero measurement was performed a month after installing the inclinometer casing - after the grout had cured (sites I2 and I3) and directly after forcing in the profiles (site I6).

Table 1. Soil parameters

\begin{tabular}{|l|c|c|c|c|c|c|c|c|}
\hline \multicolumn{1}{|c|}{ Soil type } & Thickness & $\begin{array}{c}\text { Liquidity } \\
\text { index } \\
I_{L}\end{array}$ & $\begin{array}{c}\text { Specific } \\
\text { weight } \\
\gamma\end{array}$ & $\begin{array}{c}\text { Young's } \\
\text { modulus } \\
\mathrm{E}\end{array}$ & $\begin{array}{c}\text { Poisson's } \\
\text { ratio } \\
v\end{array}$ & $\begin{array}{c}\text { Cohesion } \\
c\end{array}$ & $\begin{array}{c}\text { Internal } \\
\text { friction } \\
\text { angle } \\
\varphi\end{array}$ & $\begin{array}{c}\text { Tensile } \\
\text { strength } \\
\text { for tension } \\
\text { cut-off }\end{array}$ \\
\cline { 2 - 9 } & $\mathrm{m}$ & - & $\mathrm{kN} / \mathrm{m}^{3}$ & $\mathrm{MPa}$ & - & $\mathrm{kPa}$ & $\circ$ & $\mathrm{kPa}$ \\
\hline Till/alluvium & 1.0 & - & $18.0 / 21.0$ & 10 & 0.25 & 10 & 9 & 8,73 \\
\hline Sandy clay & 3.5 & 0.05 & $21.0 / 22.0$ & 32 & 0.29 & 33 & 21 & 25,05 \\
\hline $\begin{array}{l}\text { Sandy clay } \\
\text {-worsened } \\
\text { parameters }\end{array}$ & - & - & $21.0 / 22.0$ & 22 & 0,29 & 22 & 14 & 18,04 \\
\hline $\begin{array}{l}\text { Silty/Sandy } \\
\text { clay }\end{array}$ & 10.5 & 0.15 & $21.5 / 22.5$ & 58 & 0.29 & 47 & 24 & 34,59 \\
\hline
\end{tabular}


The measurements were performed along the inclinometer casing, at points spaced at half a metre intervals in four mutually perpendicular directions. It was assumed that displacements of the casing base were equal to zero. In the case presented, the casings were $9.0 \mathrm{~m}$ long and the excavation - only $2.0 \mathrm{~m}$ deep. The measurements, performed by means of an inclinometer set produced by SISGEO [17], took place from June 2011 to September 2014. Initially, they were performed at dense time intervals and then, after displacement stabilization, more rarely. The measurement results are shown in Figs. 1, 2, 3. Also, displacement growth over time is presented in Figs. 4, 5, 6.

The inclinometer measurements were conducted at the following measurement points:

I2 - lagging,

I3 - lagging (central part),

I6 - pile, inclinometer casing welded to the profile.

The displacements of the excavation support observed over the period of three years demonstrated the pattern of steady growth over the first two months, followed by a gradual levelling out to a final plateau.

The results of inclinometer measurements point to two basic types of displacements. They are strictly linked to the location of the research site. The graphs in Fig. 1 and Fig. 2 illustrate the displacements of the soldier-pile wall lagging for sites I 2 and I3, while the graph in Fig. 3 - pile displacement at site I6.

The displacements of the lagging are greater than pile displacements. The greatest displacements occur for the lagging over the section reaching the depth of $2.0 \mathrm{~m}$ (the bottom of the excavation), where the inflection point of the graph is observed. At this point, there is a distinct change in the graph curvature. The next inflection point is observed at the depth of about $4.0 \mathrm{~m}$, to which the excavation was temporarily deepened. Below the bottom of the excavation, one can observe a considerably high value of the measured displacements. This is due to the stiffness of the inclinometer casing surrounded by grout, which in this case works as a pile. For this reason, displacements of the upper part of the casing are transferred to its lower part. Practically, there are no displacements towards the excavation in lagging-free places. This phenomenon has been confirmed by numerical calculations (cf. Section 6). Differences have been observed between the increments at points $\mathrm{I} 2$ and $\mathrm{I} 3$, as the soil rebounded to a varying degree during the construction of the lagging (soil collapse during the installation of the lagging).

In the case of measurement point I6, the profile is deformed together with the rectangular-section tube which it is welded to.
Differences in the stiffness and the mode of work between the pile (I6) and the ABS inclinometer casing (in the soil beyond the lagging - I2, I3) result in the fact that the graph showing pile displacements does not have distinct curvatures and the inflection points are less defined. The displacement graphs show inflection points at the same depths.

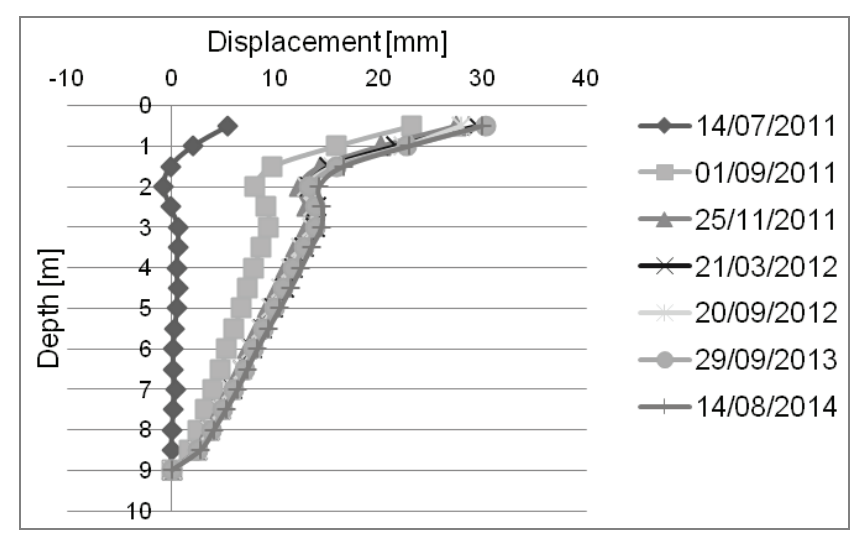

Fig. 1. Displacements from inclinometer measurements, measurement point I2

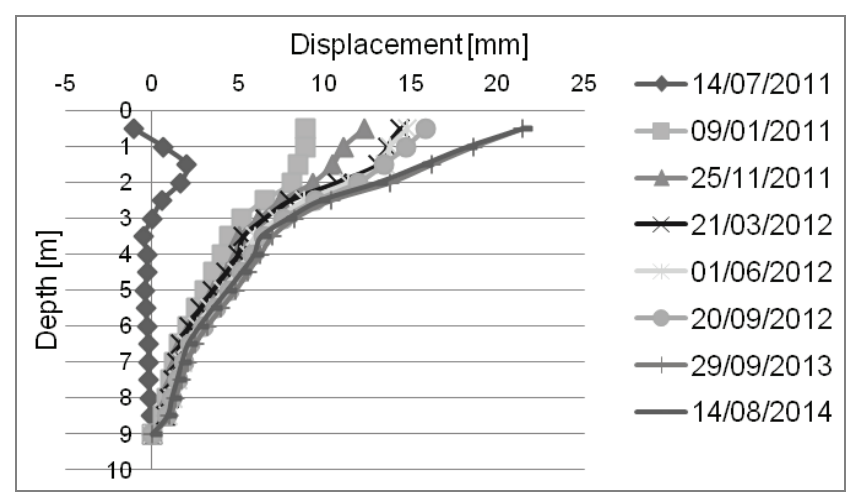

Fig. 2. Displacements from inclinometer measurements, measurement point I3

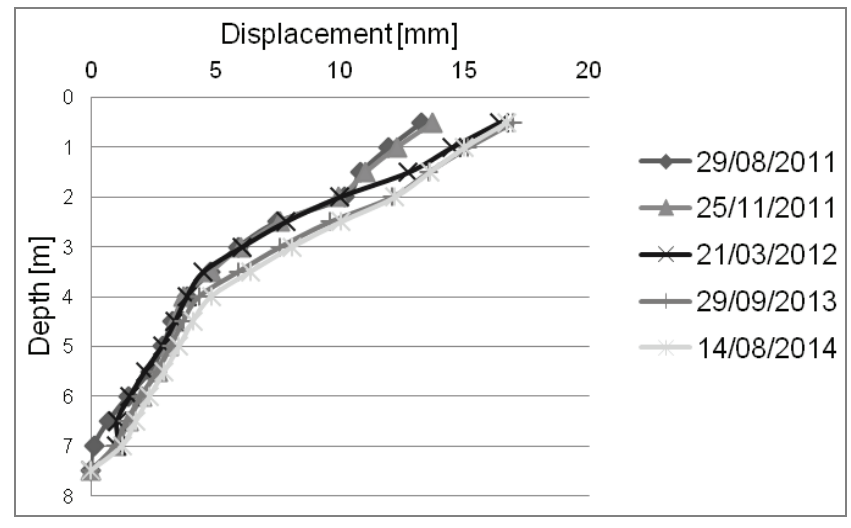

Fig. 3. Displacements from inclinometer measurements, measurement point I6 
Displacement increments stabilized after four months (sites I2, I3 and I6), but for site I3, the next discernible displacement increment occurred in the second year of observation Figs. 4-6.

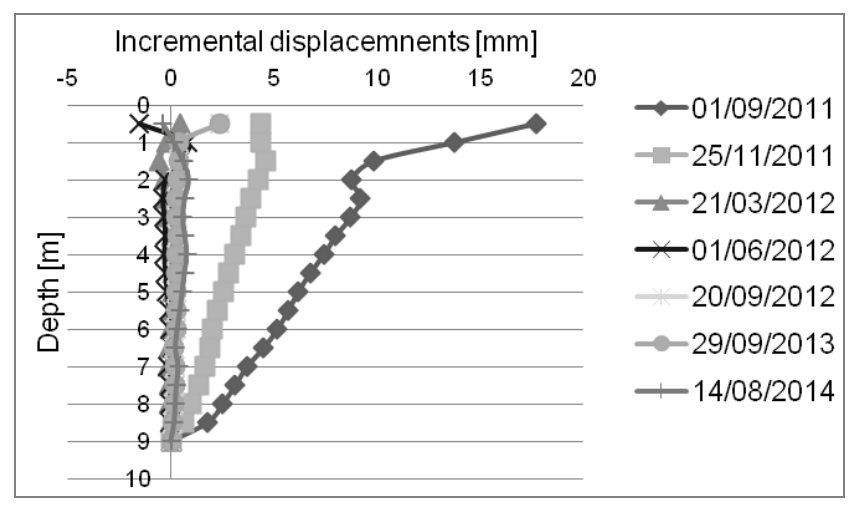

Fig. 4. Displacements

from inclinometer measurements over time, measurement point I2

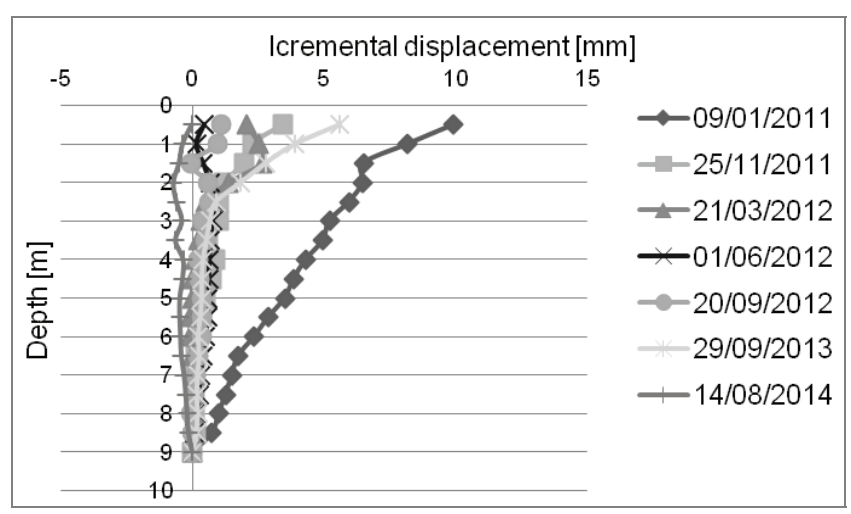

Fig. 5. Displacements

from inclinometer measurements over time,

measurement point I3

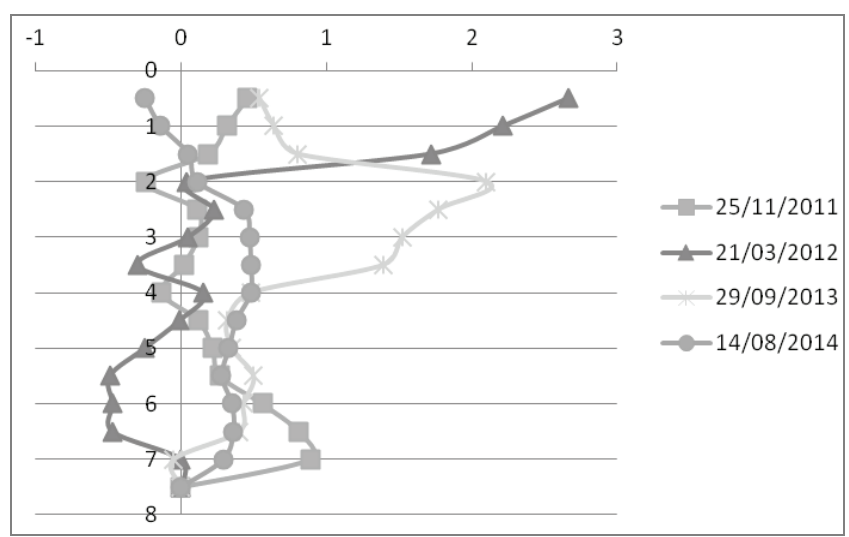

Fig. 6. Displacements

from inclinometer measurements over time, measurement point I6

\section{NUMERICAL MODELLING AND CALCULATIONS}

The calculations were performed with the aid of a 3D FEM model. A model of a composite soldier pile-lagging-soil system was developed using PLAXIS 3D [1].

A piece of a soldier-pile wall composed of five piles and four sheets of lagging between them was adopted as the computational model. Such a choice enabled minimising the boundary effect. Also, the size of the soil block was selected through successive calculations. It measured $20 \mathrm{~m}$ perpendicularly to the excavation support, $12 \mathrm{~m}$ - in the parallel direction (four times the distance between the piles) and $15 \mathrm{~m}$ in depth.

The soil layers were modelled according to Table 1. They were assumed to be homogeneous, incorporating Coulomb yield criterion with non-associated plastic flow rule. The piles were modelled as beam elements and the lagging - as plate elements with isotropic properties, see Table 2 . The connection between them enabled rotation along the beam elements and disabled all other rotations and transitions. Particular lagging panels were not interconnected, which enabled them to work independently. Interfaces were modelled on wall-ground contact surfaces. The construction was created in the Staged Construction mode of PLAXIS 3D.

Table 2. Lagging parameters

\begin{tabular}{|c|c|c|c|c|}
\hline & $d[\mathrm{~m}]$ & $\gamma\left[\mathrm{kN} / \mathrm{m}^{3}\right]$ & $\mathrm{E}\left[\mathrm{kN} / \mathrm{m}^{2}\right]$ & $v[-]$ \\
\hline Timber & 0.10 & 5 & $11 \mathrm{MPa}$ & 0.35 \\
\hline
\end{tabular}

Staged construction is a static modelling, analysis, and design application which enables defining a sequence of construction stages in which structural systems and load are added or removed, and timedependent behaviours are evaluated. Material and geometric nonlinearity may be applied to staged construction.

The excavation was deepened in stages - 1-metre deep layers - to the depth of $4.0 \mathrm{~m}$, and then filled back to the depth of $2.0 \mathrm{~m}$. This corresponds to the existing structure. The last stage consisted of deepening to the projected level of $4.0 \mathrm{~m}$ below the ground level.

The excavation was assumed to be filled with the same soil with worsened geotechnical parameters. The parameters were selected based on the agreement of calculated displacements with those measured since 
July 2011 for the lagging and the pile. The location of points of agreement is presented in Table 4. The computational model of the problem is presented in Fig. 7. Quadratic tetrahedral 10-node elements were used to create the mesh.

Table 3. Pile parameters

\begin{tabular}{|c|c|c|c|c|c|}
\hline & $A\left[\mathrm{~m}^{2}\right]$ & $\gamma\left[\mathrm{kN} / \mathrm{m}^{3}\right]$ & $\mathrm{E}\left[\mathrm{kN} / \mathrm{m}^{2}\right]$ & $I_{y}\left[\mathrm{~m}^{4}\right]$ & $I_{x}\left[\mathrm{~m}^{4}\right]$ \\
\hline H Beam & 0.01491 & 78.5 & $210 \mathrm{GPa}$ & 0.000252 & 0.000085 \\
\hline
\end{tabular}

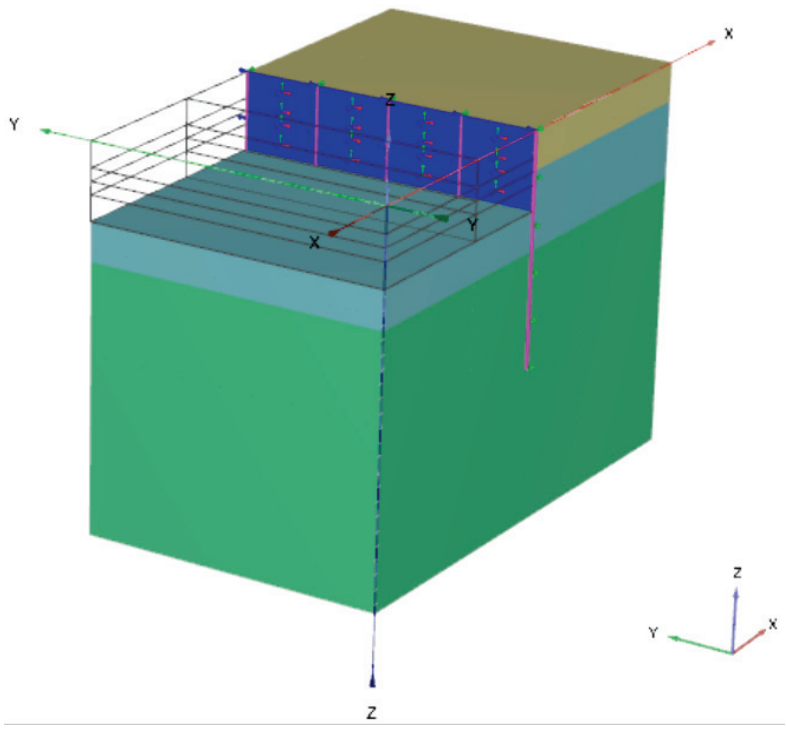

Fig. 7. Computational model
Preliminary calculations were not running smoothly. This was due to the application of relatively high cohesion in combination with a zero tension cut-off for all the materials. For the Mohr-Coulomb model, the tension cut-off is, by default, selected with a tensile strength of zero. As a result, a large number of tension points are generated behind the wall. Most of them are considered to be "inaccurate" and thus they influence the numerical procedure (Fig. 8). An example of this phenomenon are the unreliable values of $\sum M_{s f}<1.0$ (cf. Section 7).

Materials with such high cohesion as those in Table 1 will generally have some tension capacity. In numerical calculations, an area with tensile stresses has developed. According to the Coulomb envelope shown in Fig. 9, it is allowed when the shear stress is sufficiently small. This indicates that soil may fail as a result of tension as well as shear. Such behaviour can be included in PLAXIS 3D analysis by selecting the tension cut-off. Regarding tensile strengths, they can be obtained from plastic parameters according to the representation of the yield surface as shown in Fig. 9 [9], where: $\sigma_{c}$ - compressive strength, $\sigma_{t}$ - tensile strength.

After such a modification of the Coulomb model parameters, the number of tension cut-off points rapidly decreases.

Figure 10 displays a map of displacements towards the excavation occurring after the completion of this

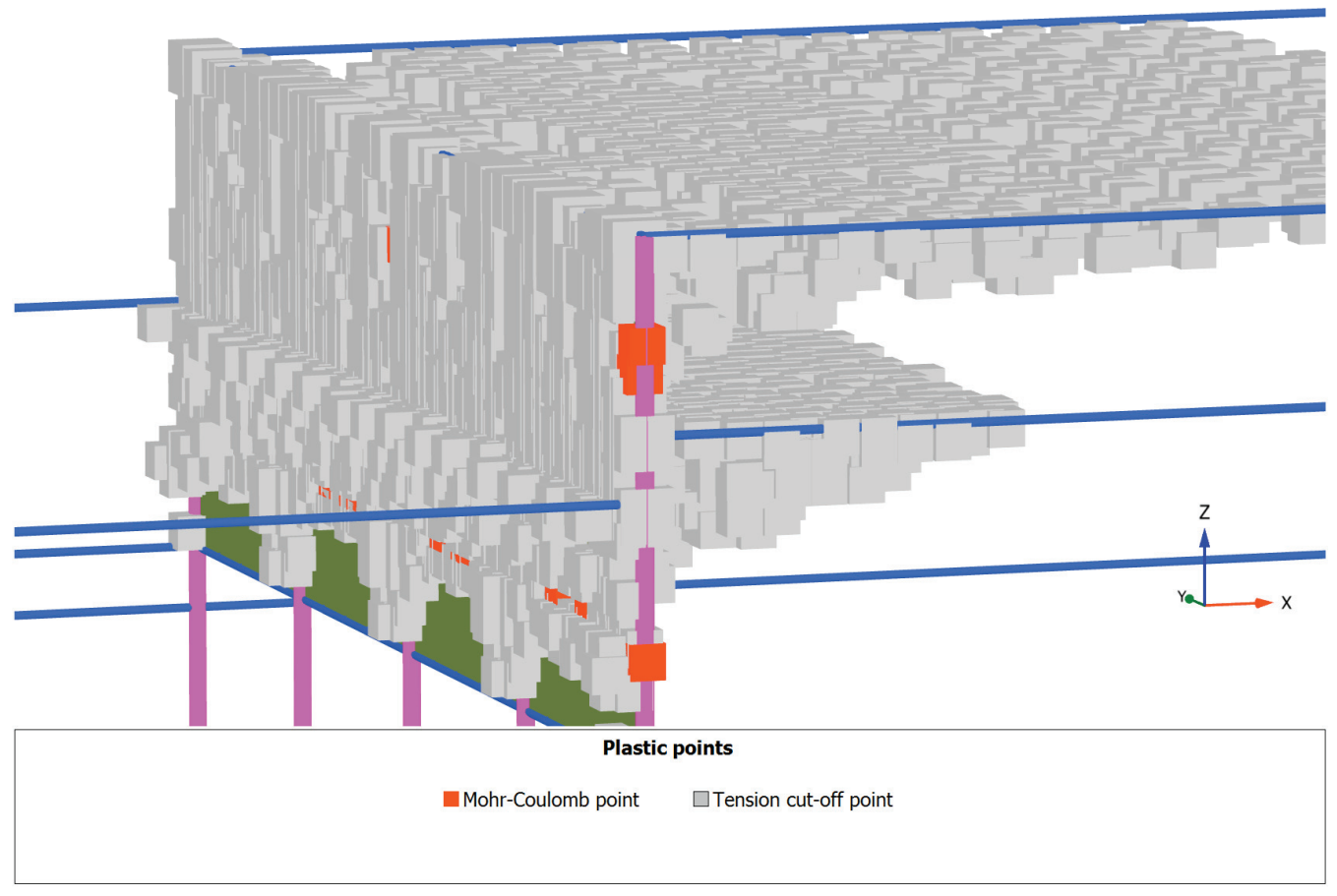

Fig. 8. Plastic points and tension cut-off points in preliminary calculations 


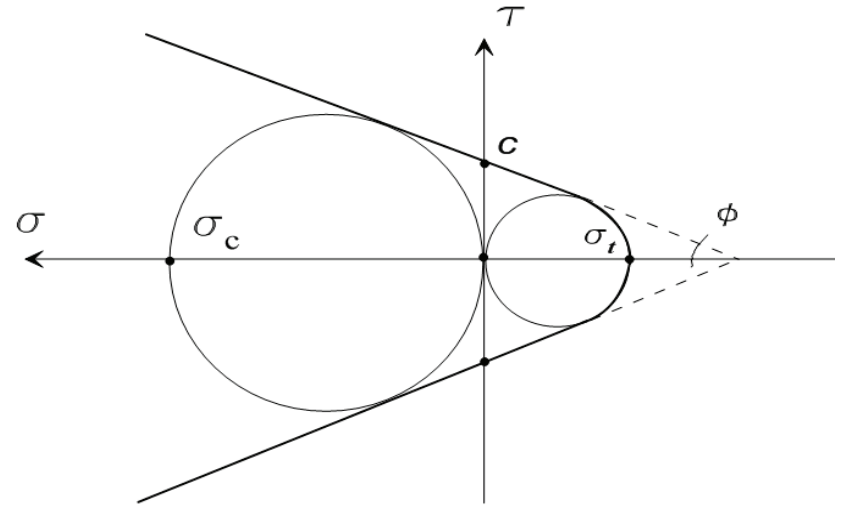

Fig. 9. Deduction of Mohr-Coulomb parameters excavation. The displacements of the top of the excavation support observed over the three years of the experiment exceeded the displacements calculated for the initial geotechnical parameters compiled in Table 1. This implies that the soil conditions deteriorated as a result of atmospheric exposure. This process is described by further calculations using the $\varphi / c$ reduction procedure.

The displacements of the pile and the lagging decreased with depth (see Figs. 11, 12). The decrease was particularly significant below the ground surface. Soil displacement occurred only at the level of the lagging (Fig. 12). The lagging displacements deter-

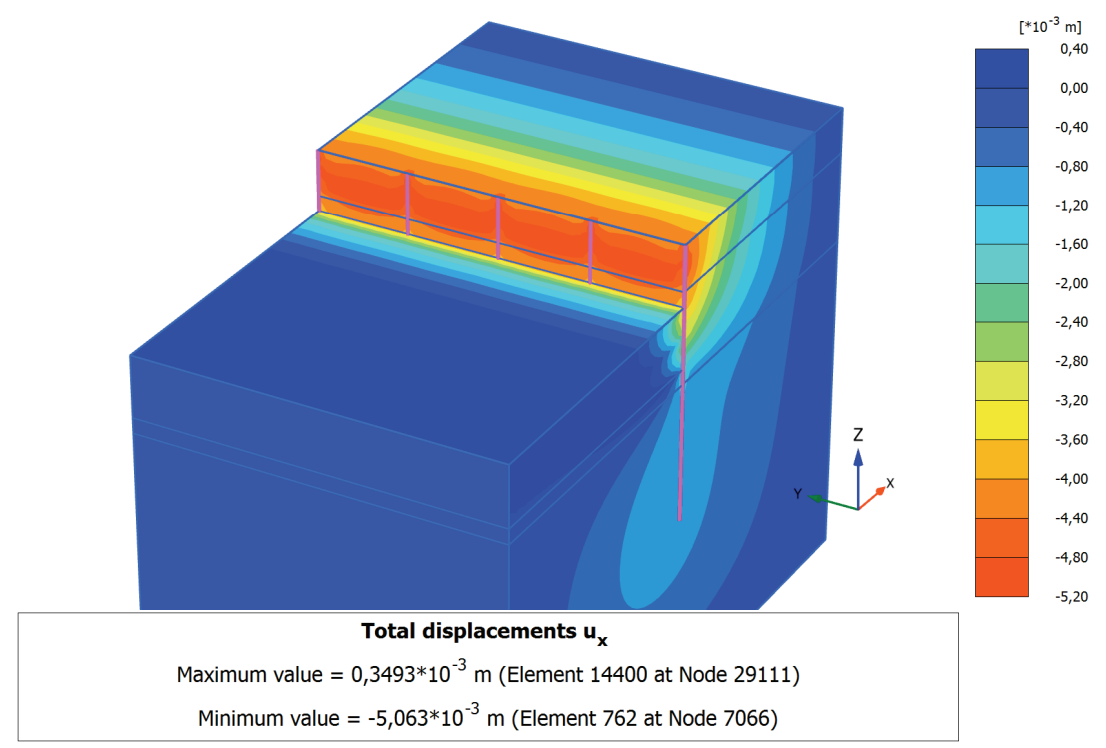

Fig. 10. Displacements of the computational model after the completion of the excavation

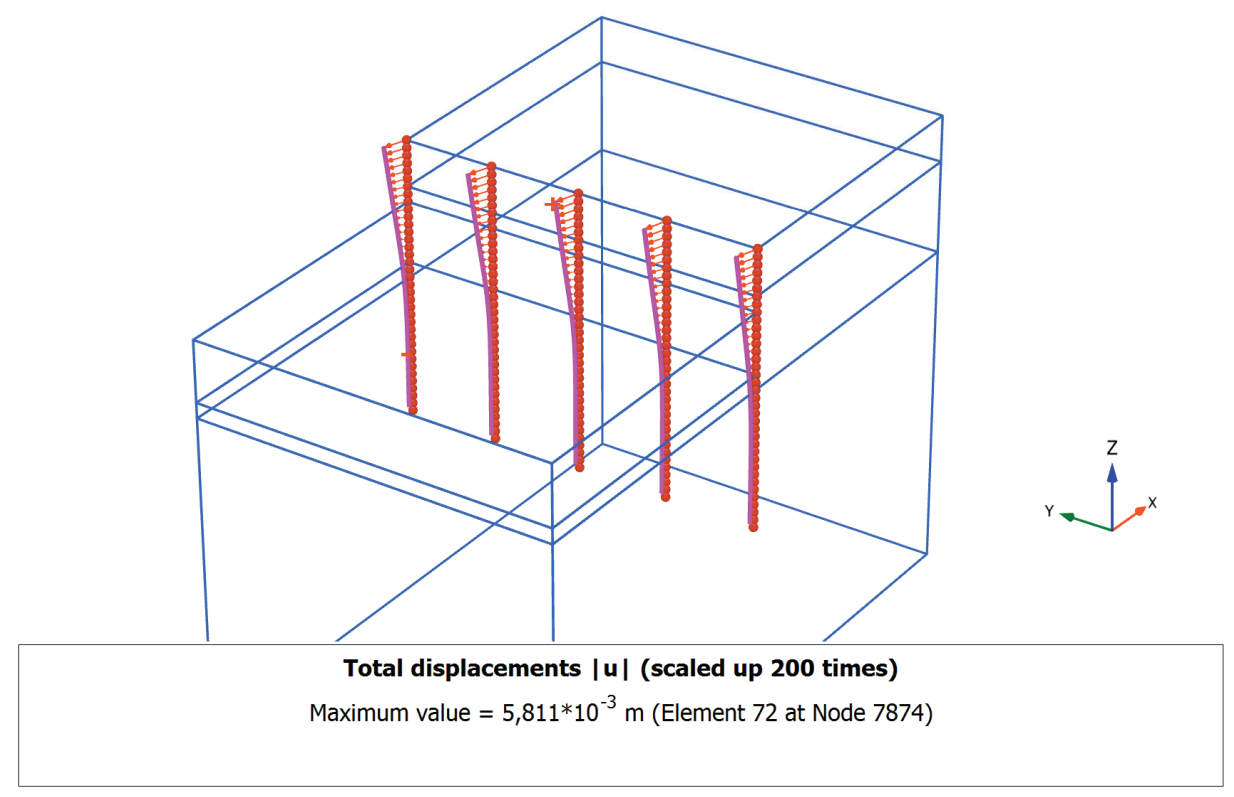

Fig. 11. Pile displacements after the completion of the excavation 


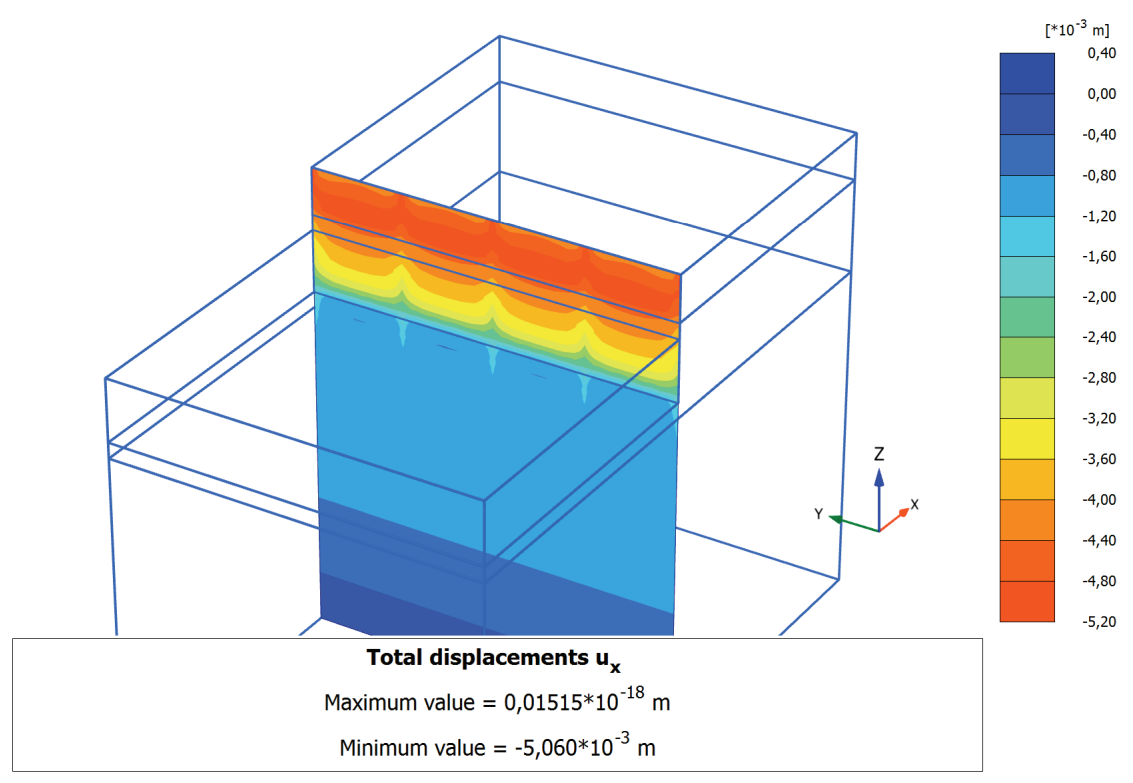

Fig. 12. Lagging displacements after the completion of the excavation

mined from inclinometer measurements conducted below the bottom of the excavation reached values higher than those suggested by numerical calculations. This is due to the stiffness of the inclinometer casing, which transferred deformations to lower measurement points.

\section{COMPUTATION OF SAFETY FACTOR $M_{s f}$}

The numerical analysis of the problem comprises calculations of the global structural safety factor depending on the displacement of the chosen points in the lagging and conducted by means of the $\varphi / c$ reduction procedure. The numerical calculations enabled estimating changes in the global safety factor $M_{s f}$ occurring during the observation of the excavation support system.

The global safety factor $M_{s f}$ is specified based on the reduction factor of soil strength parameters for which failure occurs and it is defined by the formulas [1]

$$
\sum M_{s f}=\frac{\operatorname{tg} \varphi}{\operatorname{tg} \varphi_{\text {red }}}=\frac{c}{c_{\text {red }}}
$$

$$
F S=\frac{\text { available strength }}{\text { strength at failure }}=\text { value of } \sum M_{s f} \text { at failure } .
$$

The value of incremental multiplier $M_{s f}(1)$ at the start of the calculations is 1.0. The assumed increment of safety factor $M_{s f}$ in the next calculation step is 0.10 . Strength parameters are automatically reduced until the ultimate limit state or the assumed number of calculation steps is reached.

During the procedure, zones of increased displacements and particularly of increased displacement increments are observed. These increments are due to the reduction in strength parameters $\operatorname{tg} \varphi$ and $c$ of the medium. During these calculations, the adopted soil Young's moduli remain unchanged. It is essential to define the 'moment of stability loss' and it is not an obvious issue as displacement growth is a continuous process. In this case, the limit $M_{s f}$ value is obtained with the maximum number of calculation steps, see Fig. 13a, which are associated with considerable displacements of the retaining structure, see Fig. 13b. The authors have decided to choose an alternative graphical method of determining the safety index. It consists of plotting two tangents to the displacement graph, like in Figs. 14-17.

The graphical method of safety estimation is very conservative in the sense that it recognizes stability loss quite early, when one could further load the medium or weaken it by further strength reduction. This reference mode of operation could be placed somewhere between ultimate limit state (full plasticity of all points), and critical state (plasticity of only a few isolated points under the greatest strain).

The values of global safety factors determined by means of the graphical procedure and the measured or calculated displacements are shown in Table 4 based on Figs. 14-17. 

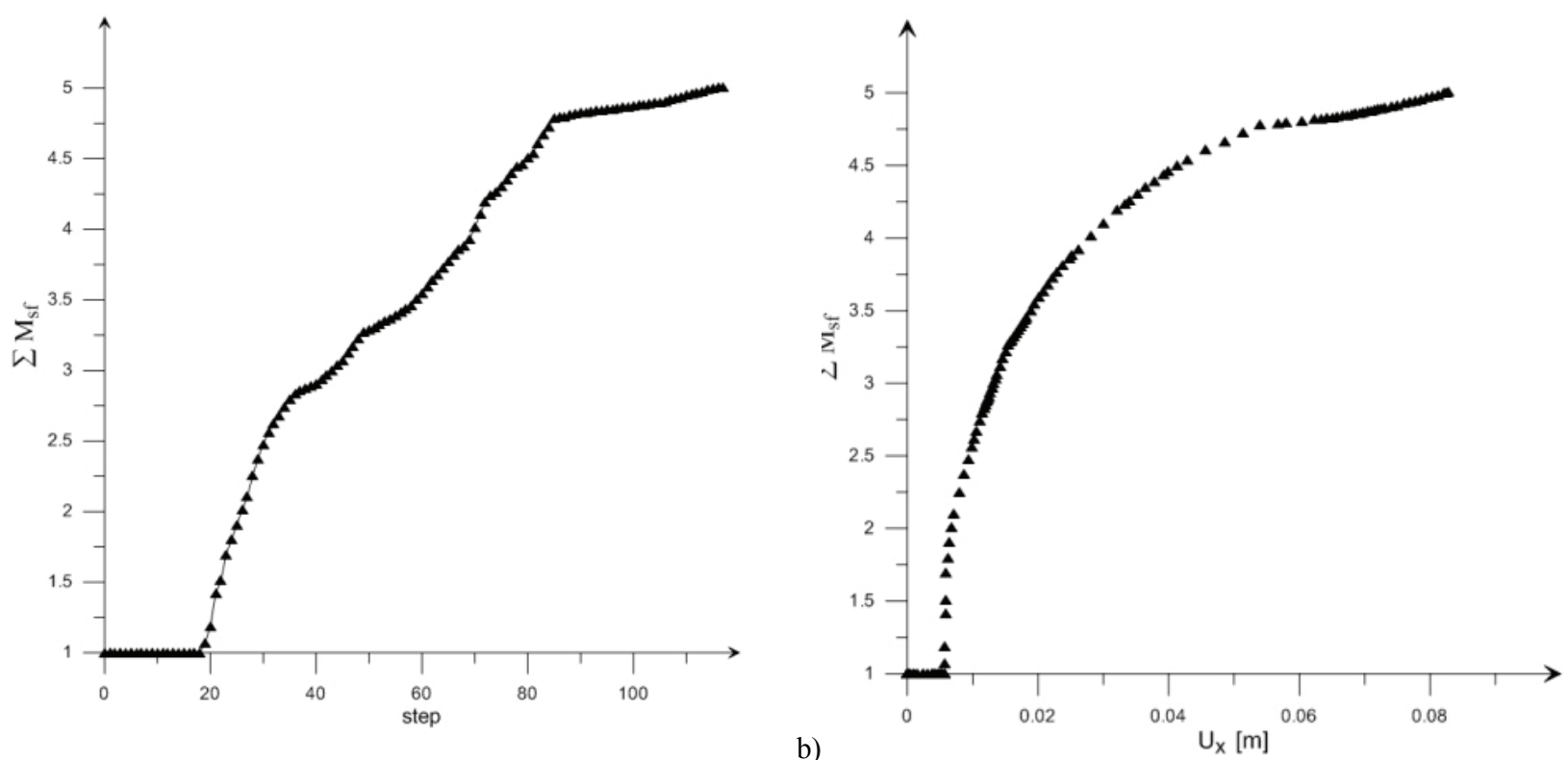

Fig. 13. $\sum M_{s f}$ calculation versus: (a) step, (b) $u_{x}$ displacements

Table 4. Point location and its safety factor values

\begin{tabular}{|c|c|c|c|c|c|c|c|}
\hline \multicolumn{8}{|c|}{ Excavation depth $2 \mathrm{~m}$} \\
\hline & \multirow[t]{2}{*}{ Point } & $\begin{array}{l}\text { Depth } \\
\text { below } \\
\text { ground } \\
\text { surface }\end{array}$ & $\begin{array}{c}M_{s f} \\
\text { value }\end{array}$ & $\begin{array}{l}\text { Displacements } \\
\text { - forecast of } \\
\text { stability loss }\end{array}$ & \multicolumn{2}{|c|}{$\begin{array}{l}\text { Displacements } \\
\text { - measured }\end{array}$} & $\begin{array}{l}\text { Displacements } \\
\text { - calculated }\end{array}$ \\
\hline & & $\mathrm{m}$ & - & $\mathrm{mm}$ & \multicolumn{2}{|c|}{$\mathrm{mm}$} & $\mathrm{mm}$ \\
\hline & & & & & \multicolumn{2}{|c|}{ I6 } & \\
\hline \multirow{4}{*}{ Pile } & A & 0 & 4.50 & 30 & \multicolumn{2}{|c|}{16.68} & 6 \\
\hline & B & 2 & 4.60 & 20 & \multicolumn{2}{|c|}{12.19} & 4 \\
\hline & $\mathrm{C}$ & 4 & - & - & \multicolumn{2}{|c|}{4.82} & 2 \\
\hline & $\mathrm{D}$ & 6 & - & - & \multicolumn{2}{|c|}{2.36} & 1 \\
\hline & & & & & I1 & $\mathrm{I} 2$ and $\mathrm{I} 3$ & \\
\hline \multirow{4}{*}{ Lagging } & $\mathrm{E}$ & 1 & 2.85 & 28 & 22.83 & 18.25 & 5 \\
\hline & $\mathrm{F}$ & 2 & - & - & 14.18 & 13.04 & 4 \\
\hline & G & 3 & - & - & 14.42 & 7.84 & 4 \\
\hline & $\mathrm{H}$ & 4 & - & - & 12.47 & 5.9 & 1 \\
\hline \multicolumn{8}{|c|}{ Excavation depth $4 \mathrm{~m}$ (only calculation results) } \\
\hline & \multirow[t]{2}{*}{ Point } & $\begin{array}{l}\text { Depth } \\
\text { below } \\
\text { ground } \\
\text { surface }\end{array}$ & $\begin{array}{c}M_{s f} \\
\text { value }\end{array}$ & $\begin{array}{l}\text { Displacements } \\
\text { - forecast of } \\
\text { stability loss }\end{array}$ & \multicolumn{2}{|c|}{$\begin{array}{l}\text { Displacements } \\
\text { - measured }\end{array}$} & $\begin{array}{l}\text { Displacements } \\
\text { - calculated }\end{array}$ \\
\hline & & $\mathrm{m}$ & - & $\mathrm{mm}$ & \multicolumn{2}{|c|}{$\mathrm{mm}$} & $\mathrm{mm}$ \\
\hline \multirow{4}{*}{ Pile } & A & 0 & 2.70 & 45 & \multicolumn{2}{|c|}{-} & 7 \\
\hline & $\mathrm{B}$ & 2 & & - & \multicolumn{2}{|c|}{-} & 6 \\
\hline & $\mathrm{C}$ & 4 & & - & \multicolumn{2}{|c|}{-} & 3 \\
\hline & $\mathrm{D}$ & 6 & & - & \multicolumn{2}{|c|}{-} & 2 \\
\hline \multirow{4}{*}{ Lagging } & $\mathrm{E}$ & 1 & 2.50 & 35 & \multicolumn{2}{|c|}{-} & 6 \\
\hline & $\mathrm{F}$ & 2 & & - & \multicolumn{2}{|c|}{-} & 5 \\
\hline & $\mathrm{G}$ & 3 & & - & \multicolumn{2}{|c|}{-} & 5 \\
\hline & $\mathrm{H}$ & 4 & & - & \multicolumn{2}{|c|}{-} & 1 \\
\hline
\end{tabular}



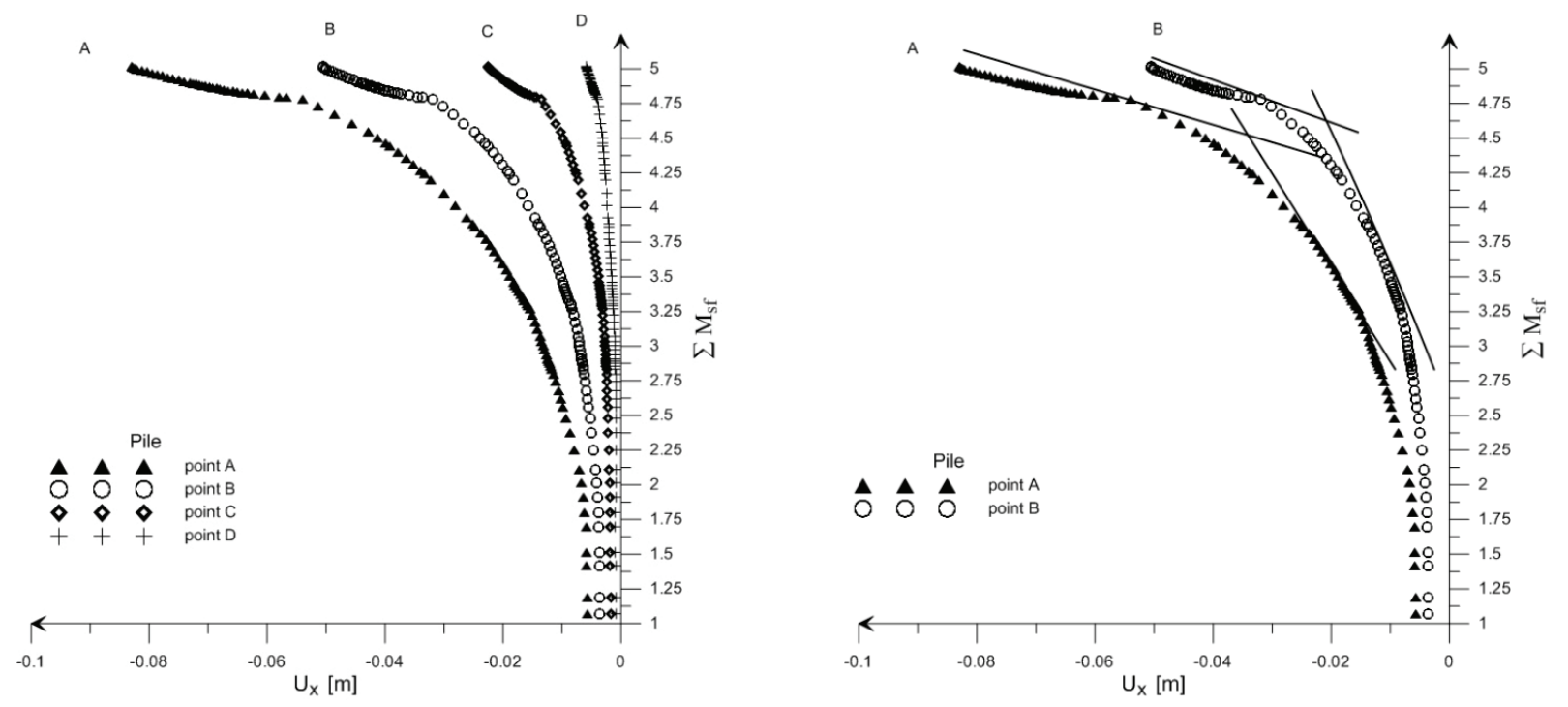

Fig. 14. Determining safety factor for measurement points in a pile (excavation depth $2 \mathrm{~m}$ )
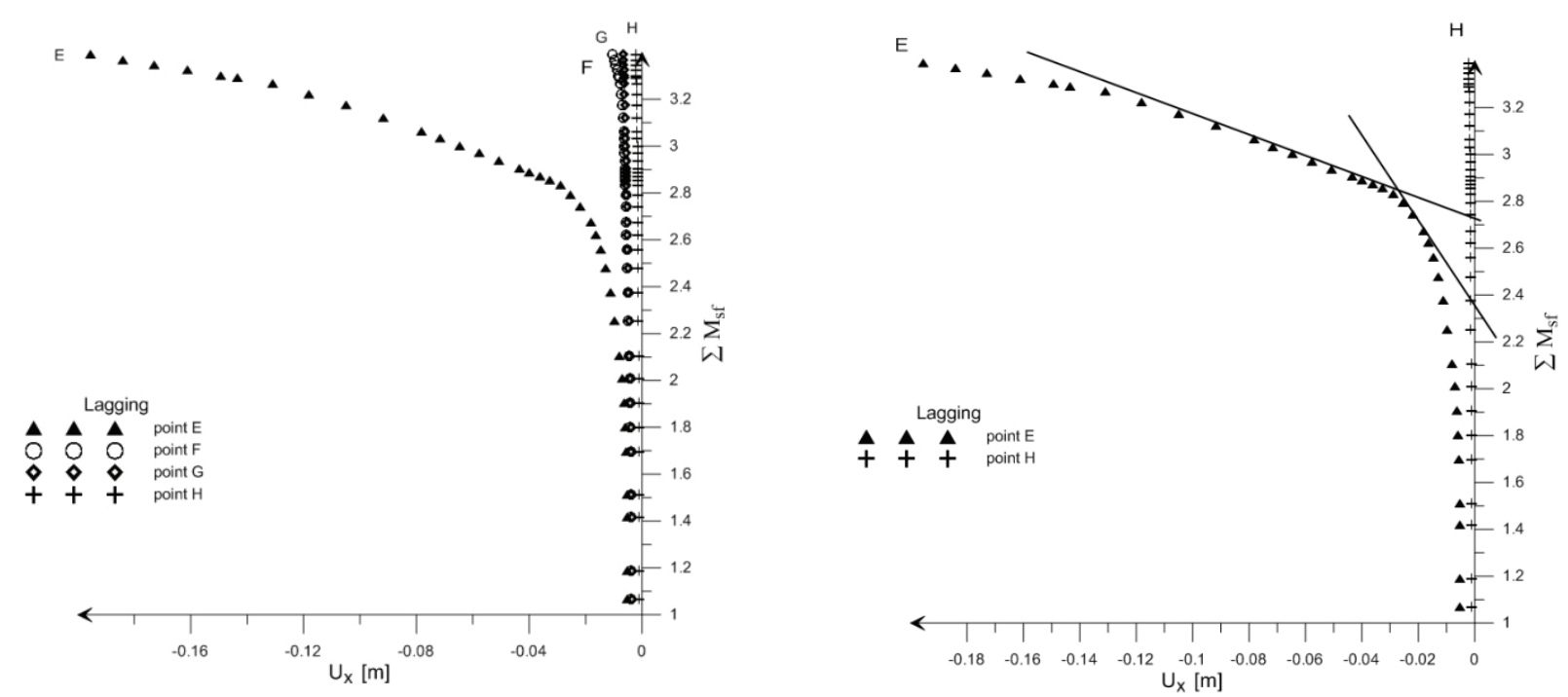

Fig. 15. Determining safety factor for measurement points in lagging (excavation depth $2 \mathrm{~m}$ )
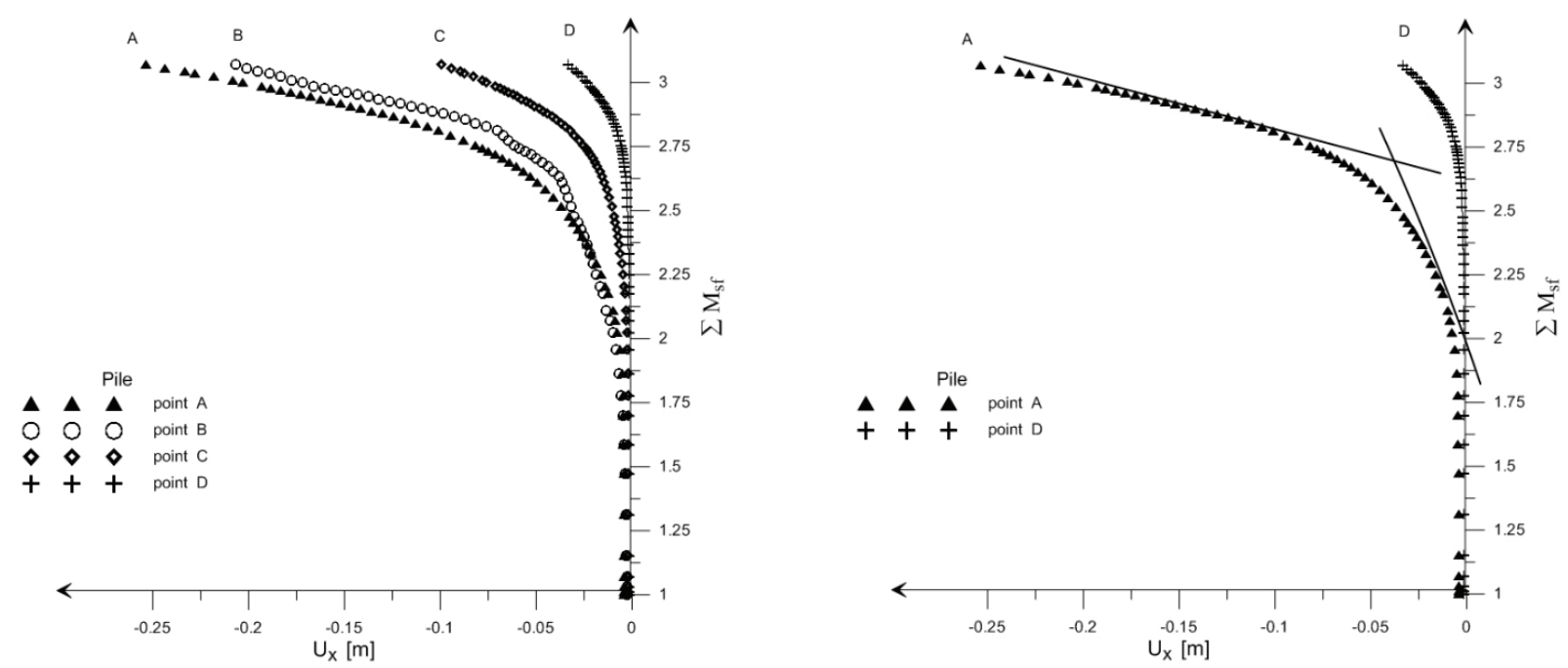

Fig. 16. Determining safety factor for measurement points in a pile (excavation depth $4 \mathrm{~m}$ ) 

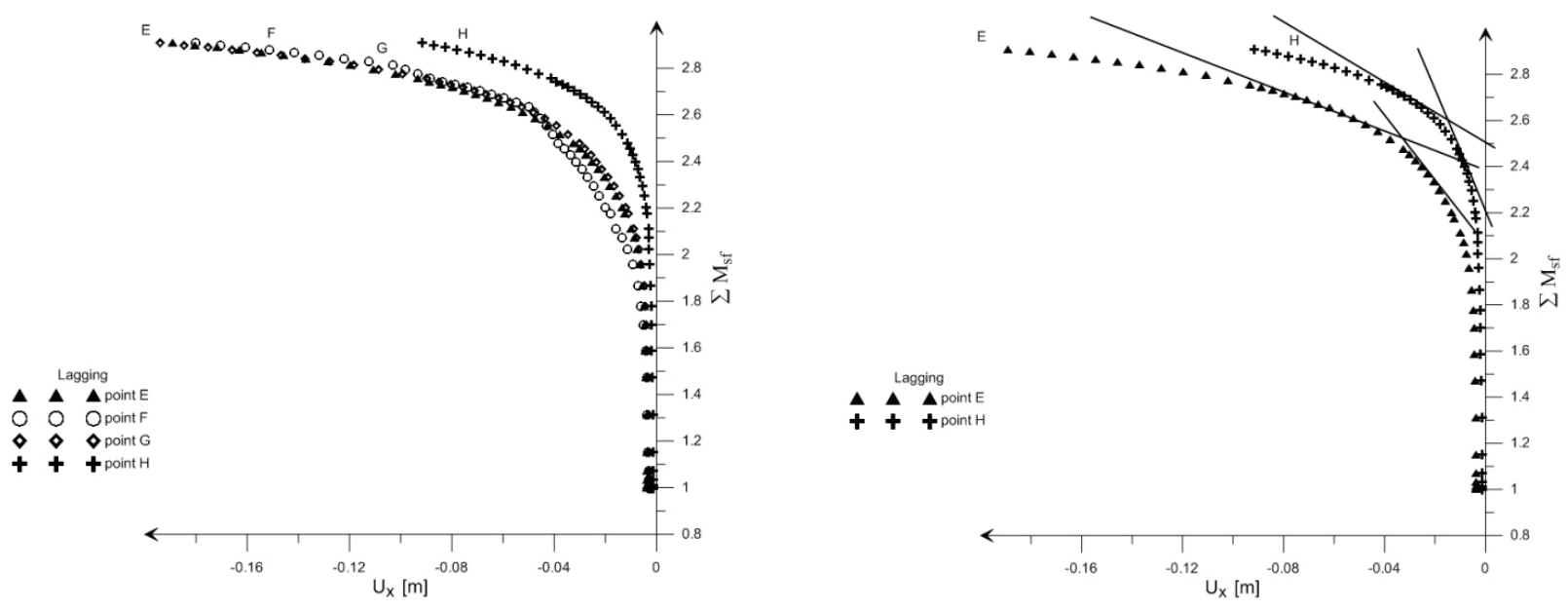

Fig. 17. Determining safety factor for measurement points in lagging (excavation depth $4 \mathrm{~m}$ )

\section{CONCLUSIONS}

Displacements of the pile and the lagging display varying values. Both the measured values and those calculated numerically show a variation for the same ordinates below the ground surface. This is due to the unique stiffness of the pile and lagging. The pile is fixed in the ground as a cantilever beam, which limits its displacement while the rotation between the lagging and the pile is free.

Soldier pile wall deformations arise a short time after the excavation is completed and they do not reveal growth over time. Nevertheless, the structure is treated as a temporary one. This results from the limited durability of the wooden lagging.

The conducted calculations enable formulating the following conclusions:

- a reduction in the geotechnical parameters $\varphi$ and $c$ has different impacts on stability loss for the lagging and the pile,

- parameter reduction enables obtaining higher values of the safety factor $M_{s f}$ for the pile than for the lagging,

- the lagging is more sensitive to the deterioration in geotechnical parameters than the pile,

- the $M_{s f}$ factors determined graphically for the pile are lower for points lying near the upper ground surface than for those embedded in the ground; a similar relation applies to points in the lagging,

- pile displacement growth over time is lower than lagging displacement growth.

The values of the $M_{s f}$ factor are relatively high and they range from 2.6 to 4.6. These values depend on the depth of the excavation and the position of points A to $\mathrm{D}$ and $\mathrm{E}$ to $\mathrm{H}$, representative of the pile and the lagging, respectively. The calculated $M_{s f}$ factors exceed the values adopted for the embankment, which are usually comprised in the interval from 1.0 to 1.5 [5]. This is caused by the fact that the structure was designed for the excavation depth of $4.0 \mathrm{~m}$. The depth was reached briefly during the installation of the lagging. The excavation depth is generally $2.0 \mathrm{~m}$

The displacement values achieved at the time of the predicted stability loss are over $3 \mathrm{~cm}$ for the pile and $3.5 \mathrm{~cm}$ for the lagging in a $2 \mathrm{~m}$ deep excavation. A downward trend is observed for representative points. The obtained ultimate displacements are larger than those measured in the field. Movements of the soldier pile for the designed excavation depth of $4 \mathrm{~m}$ should not exceed $4 \mathrm{~cm}$ and $5 \mathrm{~cm}$ for the pile and the lagging, respectively.

The observed structure is treated as a temporary one. In this case, the observation time is three years, which is longer than the usual durability warranty. The calculations performed show that the designed excavation with the depth of $4.0 \mathrm{~m}$ is safe. After the deepening, it is necessary to assess the technical condition of the structure, in particular, the lagging buried in the ground, because the embedded wood is not impregnated. A study to determine wood durability in underground environment was conducted by Highley [10]. Weather conditions, board size and the kind of structural joint used all affect the expected average life. The estimated average life of pine wood varies from 9 to 20 years.

The proposed finite element method of determining safety factor by means of strength reduction produces results which are consistent with those from Bishop's slip-circle method. The advantage of this method as compared to classical methods is that it can deal with the most complex kinds of geotechnical systems [2]. The method presented does not have to 
predefine the failure mechanism, because of its highly three-dimensional work.

The strength reduction technique, which is only available with numerical calculations, allows for the separation of the $M_{s f}$ factor for the pile and the lagging. The classic calculation methods [8] do not differentiate the stiffness of the pile and the lagging. The only element which is taken under consideration is the soldier pile. It is calculated as a laterally loaded pile.

An analysis of the problem where the numerical model of a soldier-pile wall is based on the observed displacements, after deepening the excavation to the projected depth of $4.0 \mathrm{~m}$, will be a subject for future studies.

\section{REFERENCES}

[1] Brinkgreve R.B.J., Engin E., Swolfs W.M., Plaxis 3D 2012, Plaxis bv, 2012.

[2] Brinkgreve R.B.J., BAKKeR H.L., Non-linear finite element analysis of safety factors, Computer Methods and Advances in Geomechanics, Balkema, Rottedam, 1991, 1117-1122.

[3] Broms B., The lateral resistance of piles in cohesive soils. Journal of the Soil Mechanics \& Foundation Division, ASCE, 1964, 90 SM3, 123-156.

[4] Broms B., The Lateral Resistance of piles in cohesive soils. Journal of the Soil Mechanics\& Foundation Division, ASCE, 1964, 90 SM2, 27-63.

[5] DAwSOn E.M., Roth W.H., DreSChER A., Slope stability analysis by strength reduction Geotechnique, 1999, 49 (6), 835-840.

[6] DunNiclifF J., Geotechnical Instrumentation for Monitoring Field Performance, Wiley, New York, 2004.

[7] FAJGA S., Dokumentacja Geotechniczna dla określenia warunków gruntowo-wodnych $i$ oceny stanu czystości gruntu dla projektowanej budowy we Wrockawiu pomiędzy ul. Eugeniusza Horbaczewskiego/Bystrzyckiej/Na Ostatnim Groszu, GEO2000, 2007.
[8] GERMAN GEOTECHNICAL SOCIETY, Recommendations on Excavations EAB, Wiley-VCH Verlag $\mathrm{GmbH}$, 2014.

[9] HadziJanev ArdiaCa D., Mohr-Coulomb parameters for modelling of concrete structures Plaxis Bulletin, Vol. 25, Spring 2009, 12-15.

[10] Higley T.L., Comparative durability of untreated wood in use above ground, International Biodeterioration \& Biodegradation, 1995, 63(1), 409-419.

[11] Kozubal J., PuŁa W., WyjadŁowski M., Bauer J., Influence of varying soil properties on evaluation of pile reliability under lateral loads, Journal of Civil Engineering and Management, 2013, 19 (2), 272-284, DOI: 10.3846/13923730.2012.756426.

[12] MATLOCK H.R.L., Generalized solutions for laterally loaded piles. Journal of Soil Mechanics Foundation DivisionASCE; 1960,86(5), 63-91.

[13] O’Neill M.W., Gazioglu S.M., An evaluation of $p-y$ relationships in sands. A report to the American Petroleum Institute, PRAC 82-41-1. University of Houston Texas, 1983.

[14] O’Neill M.W., Murchison J.M., An evaluation of p-y relationships in clays. A report to the American Petroleum Institute, PRAC 82-41-2. University of Houston Texas, 1984.

[15] PAN D., SMethurst J.A., POWRIE W., Limiting pressure on a laterally loaded pile in a frictional soil Géotechnique Letters, Vol. 2, Issue April-June, June 2012, 55-60.

[16] Reese L.C, VAn IMPE W.F., Single Piles and Pile Groups Under lateral Loading, A.A. Balkema, Rotterdam, Brookfield 2001.

[17] SISGEO S.r.1. Inclinometers. Instruction manual, 09/05-Rev.4.

[18] URBAŃSKi A., A Simplified computational model for a periodic system of horizontally loaded piles, Computational Geomechanics ComGeo III edited by S. Pietruszczak \& G.N. Pande International Centre for Computational Engineering (IC2E) Rhodes, Greece \& Swanesea, 2014, 516-524.

[19] Zhang L.M., NG A., Probabilistic limiting tolerable displacements for serviceability limit state design of foundations, Geotechnique; 2005, 55(2), 151-161.

[20] EN 1997-1:2008. Eurocode 7. Geotechnical Design. Part 1. General Rules. CEN, Brussels. 